\title{
CPW fed SRR loaded monopole antenna for triple band operations
}

\author{
Smitha K. M. ${ }^{1}$, Aju John K. K. ${ }^{2}$, Thomaskutty Mathew ${ }^{3}$ \\ ${ }^{1,2}$ School of Technology and Applied Sciences, M.G. University Regional center, India \\ ${ }^{3}$ School of Technology, GITAM University, India
}

\begin{tabular}{l} 
Article Info \\
\hline Article history: \\
Received May 24, 2019 \\
Revised Dec 7, 2019 \\
Accepted Dec 11, 2019
\end{tabular}

Keywords:

CPW fed

Monopole antenna

Split ring resonator

Triple band

\section{Corresponding Author:}

Thomaskutty Mathew, School of Technology, GITAM Deemed to be University, Bengaluru campus, Nagadenahalli, Bengaluru, India. Email: drtkmathew@gmail.com

\begin{abstract}
A planar CPW fed SRR loaded monopole antenna based on split ring resonator with triple-band operations is reported for passive UHF RFID, Wireless Local Area Networks (WLAN) and World Interoperability for Microwave Access (WiMAX) applications. Measured and simulated results show the effect of tapering of the SRR layer on bandwidth improvement and gain enhancement in comparison to monopole with SRR antenna. The CPW fed SRR loaded monopole antenna has a bidirectional pattern with high gain for wireless communication applications.
\end{abstract}

Copyright $\odot 2020$ Institute of Advanced Engineering and Science. All rights reserved.

\section{INTRODUCTION}

The antenna is an irreplaceable component of the wireless communication system and is a matching component between sources of electromagnetic energy and free space [1]. It is possible to integrate several wireless systems into a single platform with the use of multiband antennas, which means the reduction of cost and ease of use, especially in WLAN and WiMAX applications. So Antennas with multiband characteristics have gained extensive attention. Some limitations accompanying antennas are limited gain, the directivity of their radiation pattern, their physical size, their efficiency and operation at a single frequency. Many researchers reported a variety of antennas for improving the above drawbacks. Due to the advantages of low profile, low cost, broadband operating bandwidths, and simple structure, the application of printed monopole antennas are increased for the past few years [2-4].

The optimum performance of the antenna is determined by feeding methods. CPW-fed antennas are preferred because of their outstanding features, including the simple configuration of a single metallic layer, the elimination of the complex interconnection with via and solder pads, less coupling with nearby RF components and ease of integration with active MMIC devices. In 1969, Cheng P. We invented Coplanar Waveguide (CPW) which is an alternative to Microstrip and Stripline that place both the signal and ground currents on the same layer. The planar transmission line structure with ground and radiation patch on the same layer is called a coplanar waveguide structure. Various types of coplanar waveguide antennas are reported with goals of multiband, broadband miniaturization [5, 6]. Asymmetric CPW grounds (rectangular and inverted L-shaped) with the slot monopole antenna for achieving the triple-band characteristics were reported. Researchers have explored a lot of antennas based on CPW fed monopole antenna with SRR structures for multiband and broadband applications. 
Split Ring Resonator (SRR) is composed of two coupled conducting rings with splits in opposite sides printed on a dielectric slab having a relatively larger loss and narrower bandwidth. SRR replaced other methods like loading of series capacitors and shunt inductors for the realization of planar metamaterials with negative permeability. Broadside coupled split ring resonators have smaller electrical size compared to edge coupled SRR [7-11]. Different SRR based monopole antennas are reported by modifying parameters of SRR with the miniaturization of the antenna [12-14]. The equivalent inductance of the SRR is increased with tapering the SRR and the equivalent capacitance of the SRR is decreased with an increase in the gap and inter-ring spacing. Thus, the tapered SRR can be designed with the same resonant frequency as the uniform SRR. However, the tapered SRR has wider bandwidth compared to the uniform SRR $[15,16]$.

The same radiation pattern in the region above the ground as a half-wave dipole in free space can be achieved with the help of the $\lambda / 4$ monopole antenna [17]. The radiated power of monopole is only half as much power as the dipole. Planar monopole antenna exhibits many attractive features, such as simple structure, inexpensive easy integration with monolithic microwave integrated circuits (MMIC), low-profile, comfortable to planar and non-planar surfaces. Linearly polarized (LP) and Circularly Polarized (CP) operations were achieved by a multi-band coplanar monopole antenna with various structures [18]. Planar monopole antennas can be optimized to provide extremely wide impedance BW with acceptable radiation performance.

The radio frequency identification (RFID) system in the Ultra High Frequency (UHF) band of 860-960 MHz range has gained importance as it provides a longer read range and fast reading speed.UHF tags have good non-line-of-sight communication capability and a higher data rate and a typical read range of up to $5 \mathrm{~m}$ [19-20]. Different multi-band antennas have recently been proposed for WLAN (Wireless Local Area Network) that meets the standards of $2.4 \mathrm{GHz} / 5.2 \mathrm{GHz} / 5.8 \mathrm{GHz}$ and the World Interoperability for Microwave Access (WiMax) operating at 3.5GHz WiMAX IEEE 802.16 (3.4-3.6 GHz) [21-25].

In this paper, the CPW fed SRR loaded monopole antenna is presented which is useful for tripleband operations. The lower band is applicable to the UHF RFID range and the higher two bands are suitable for WLAN and WiMAX applications. It has been observed that by adjusting the width of the SRR, resonant frequency and bandwidth of the proposed antenna can be controlled.

\section{ANTENNA DESIGN}

A CPW fed planar monopole antenna with tapered SRR which uses inexpensive FR4 substrate with $1.6 \mathrm{~mm}$ thickness and relative permittivity of 4.4. is presented. Here the SRR structures are used to enhance the radiating properties of monopole antenna due to the effect of coupling between SRR and radiating element. The antenna excitation is through a CPW feed line. The center strip made of a conductor is separated by a narrow gap from two ground planes on either side as in Figure 1(a). Monopole antenna is coupled with the same SRR on the left side and right side with a gap between the monopole antenna. Here the splits in the rings are placed opposite to each other which makes the SRR resonant at wavelengths much larger than the dimensions of the rings due to the large capacitance in the gap between them. The multi-band operation can be achieved by the combination of the monopole antenna and the SRR. As no additional matching network is required, a significant improvement in the antenna characteristics can be done by using coplanar waveguide instead of microstrip feeds. The reason for choosing a rectangular SRR over a similar circular one is its lower magnetic resonant frequency and easier fabrication. Split ring resonators (SRRs) are placed on both sides of the center strip as in Figure1(b) which are coupled to the monopole antenna. Due to the coupling, the electric and magnetic fields of the monopole interact with the SRR by exciting both the inner and outer split rings. The schematic diagram of the proposed monopole antenna is shown in Figure 2(a). Figure 2(b) represents the fabricated antenna structure and measurement setup. The dimensions of proposed CPW Fed SRR loaded monopole antennas are given in Table 1.

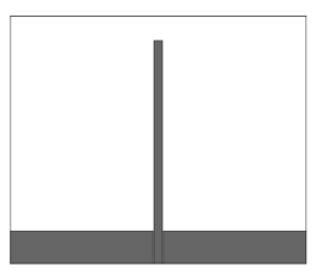

(a)

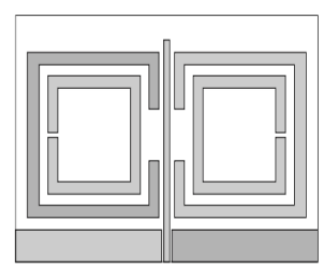

(b)

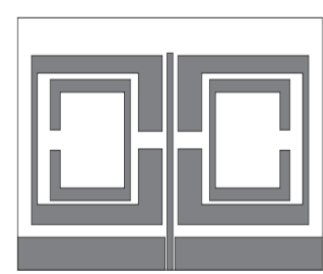

(c)

Figure 1. Structures CPW-Fed planar monopole antenna, (a) basic monopole antenna, (b) monopole antenna with uniform SRR, (c) monopole antenna with tapered SRR 


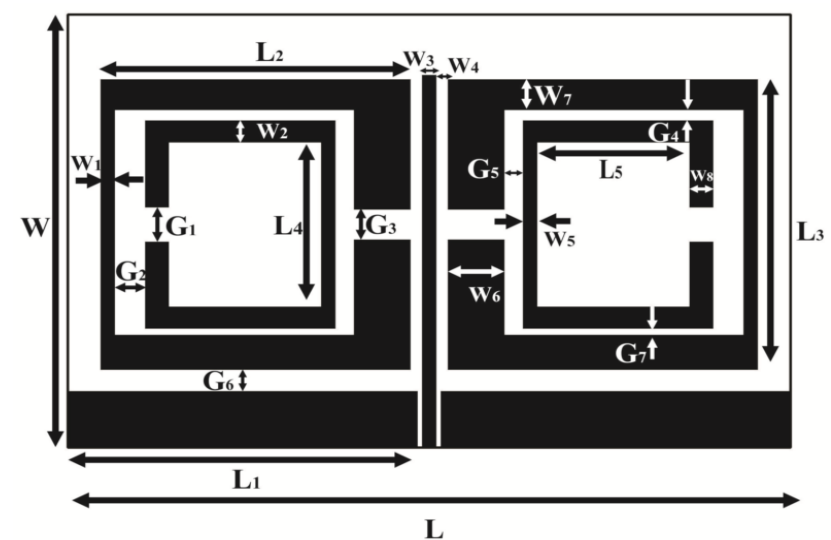

(a)

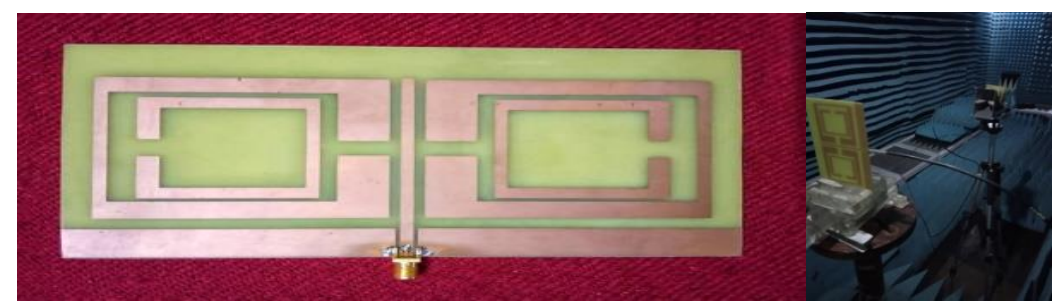

(b)

Figure 2. (a) Schematic diagram of the proposed monopole antenna,

(b) Physical view of fabricated antenna and measurement set up

Table 1. Optimal dimensions of the proposed antenna

\begin{tabular}{cccc}
\hline Parameters & Unit(mm) & Parameters & Unit(mm) \\
\hline L & 154 & W5 & 3 \\
W & 100 & W6 & 12 \\
L1 & 74 & W7 & 8.3 \\
L2 & 66 & W8 & 5.5 \\
L3 & 67 & G1 & 8 \\
L4 & 48 & G2 & 8 \\
L5 & 32.5 & G3 & 7 \\
W1 & 52 & G4 & 2.8 \\
W2 & 5 & G5 & 2 \\
W3 & 3 & G6 & 5 \\
W4 & 2.7 & G7 & 1.9 \\
\hline
\end{tabular}

The unit SRR cell is modeled as a series resonator with inductance $\mathrm{Lr}$, capacitance $\mathrm{Cr}$, and resistance $R r$. The resonant frequency is given by:

$$
\omega_{0}=2 \pi \mathrm{f}_{0}=\frac{1}{\sqrt{\mathrm{Lr} C r}}
$$

The resonant frequency can be varied by changing the SRR's equivalent capacitance and inductance. The effective inductance depends on metal rings of SRR and Effective capacitance is determined by the gaps and slits in the rings. But when the equivalent inductance is increased by widely spaced narrow rings, the equivalent capacitance will be reduced and vice versa. SRR with tapered edges is suitable for increasing the equivalent inductance and capacitance of an SRR structure simultaneously. This type of increase will provide a high level of miniaturization and better radiation characteristics.

The bandwidth for the structure:

$$
\mathrm{BW}_{\mathrm{L}}=\sqrt{\frac{\mathrm{Lr}}{\mathrm{Cr}}} \cdot \frac{(\alpha \mathrm{F})^{2}}{2 /(2 \mathrm{Z} 0)}
$$

The relative bandwidth of SRR loaded in the system is increased by enlarging the fraction F, the fraction, the cell volume occupied by the split ring and the ratio of $\frac{\mathrm{Lr}}{\mathrm{Cr}}$. So by increasing this ratio, the bandwidth of SRR can be controlled [16]. The tapered antenna is shown in Figure 1(c) with non-uniform edges of SRR. 


\section{RESULTS AND ANALYSIS}

The structure was presented for making bandwidth enhancement with the non-uniformity in the width of edges of SRR. Bandwidth improvement and shifting of resonant frequency to higher frequency occur at all frequency bands with gain improvement. Figure 3 (a) shows the simulated reflection coefficients of the base and proposed monopole antennas. As predicted by the theory, Figure 3 shows that by adapting the segment width of the SRRs, the resonant frequency is increased by about $7 \%$ from $0.8152 \mathrm{GHz}$ for the uniform SRRs to $0.8941 \mathrm{GHz}$ in the case of tapered SRRs for the first band, $38 \%$ from $1.4088 \mathrm{GHz}$ for the uniform SRRs to $2.271 \mathrm{GHz}$ in the case of tapered SRRs for second band and $2 \%$ from $3.629 \mathrm{GHz}$ for the uniform SRRs to $3.701 \mathrm{GHz}$ in the case of tapered SRRs for the third band, Furthermore, the fractional bandwidth is increased from $5.7 \%$ to $10.6 \%$ for first band, $9.9 \%$ to $10.1 \%$ for second band and $3.8 \%$ to $8.1 \%$ for third band. Table 2 compared all the results of CPW Fed SRR loaded monopole antenna.

Table 2. Comparison of simulated and measured results

\begin{tabular}{cccccccccc}
\hline Parameters & \multicolumn{3}{c}{ Monopole with SRR(Simulated) } & \multicolumn{3}{c}{ Monopole with tapered } & \multicolumn{3}{c}{$\begin{array}{c}\text { Monopole with tapered } \\
\text { SRR (Mimulated) }\end{array}$} \\
& \multicolumn{3}{c}{ SReasured) } \\
\hline Frequency band (GHz) & $0.7944-$ & $1.3156-$ & $3.5627-$ & $0.86135-$ & $2.1822-$ & $3.5959-$ & $0.85-$ & $2.14-$ & $3.56-$ \\
& 0.8412 & 1.4548 & 3.7019 & 0.90821 & 2.3955 & 3.8054 & 0.9452 & 2.37 & 3.86 \\
Resonant frequency (GHz) & 0.8152 & 1.4088 & 3.629 & 0.88412 & 2.278 & 3.6952 & 0.8941 & 2.271 & 3.7011 \\
Gain (dBi) & 3 & 5.84 & 5.71 & 2.99 & 5.68 & 8.19 & 2.98 & 5.66 & 8.1 \\
Bandwidth (MHz) & 46.815 & 139.21 & 139.21 & 54.264 & 213.35 & 209.43 & 95 & 230 & 300 \\
\hline
\end{tabular}

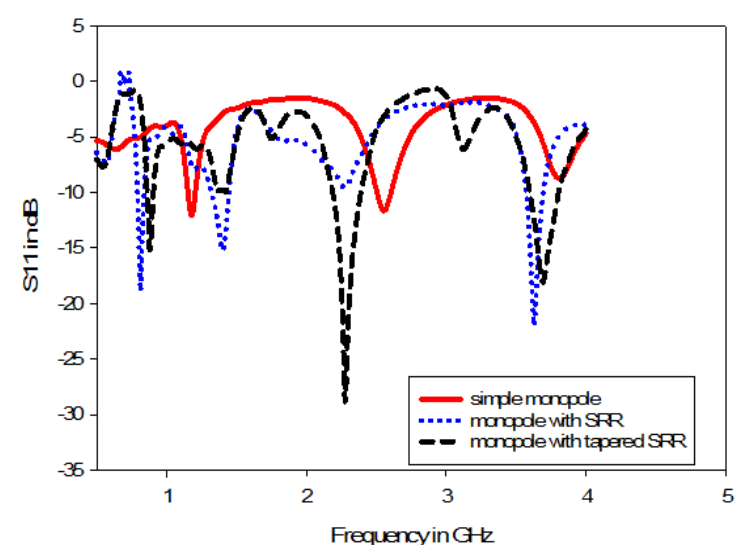

(a)

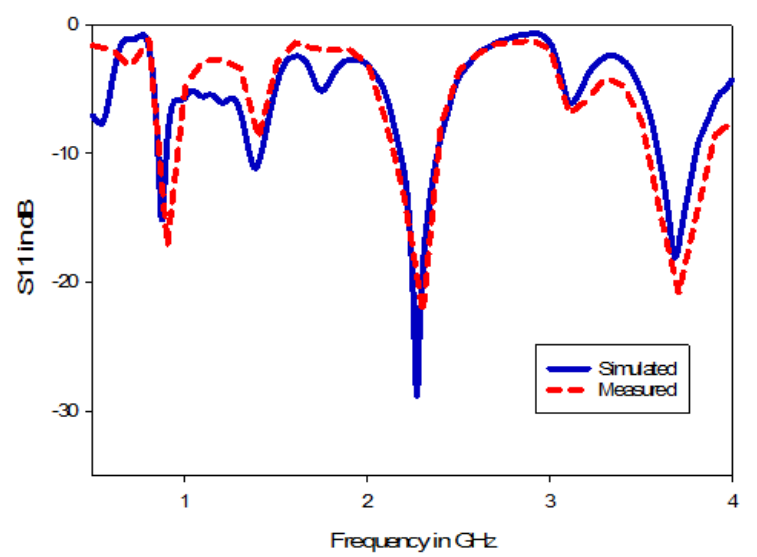

(b)

Figure 3. Variations of reflection coefficients with frequency for CPW fed tapered SRR loaded monopole antenna, (a) Simulated reflection coefficients of proposed monopole antenna $\left(\mathrm{S}_{11}\right)$,

(b) Measured reflection coefficients of proposed monopole antenna $\left(\mathrm{S}_{11}\right)$

The measured results of CPW fed SRR loaded monopole antenna based on split ring resonator show that frequency bands of $\mathrm{S} 11 \leq-10 \mathrm{~dB}$ are as follows: $0.85-0.9452 \mathrm{GHz}, 2.14-2.37 \mathrm{GHz}$ and $3.56-3.86 \mathrm{GHz}$, which will cover UHF RFID (860-960MHz), WLAN (2.4 GHz) and WiMAX (2.3/2.5/3.5/ GHz) frequency bands. Figure 3(b) compares simulated and measured $\mathrm{S}_{11}$ in $\mathrm{dB}$. The radiation patterns showing co and cross polarization of E-plane and $\mathrm{H}$-plane at resonant frequencies $0.88414 \mathrm{GHz}, 2.787 \mathrm{GHz}$ and $3.6987 \mathrm{GHz}$ are in Figures 4, 5 and 6 respectively.

Table 3 shows a comparison of proposed work with recently published papers for triple-band operations achieved using CPW fed monopole antenna. Even though the size of the antenna is large compared to the other two papers, the proposed work gives a band for RFID applications along with the other two bands useful for WLAN/WiMAX applications. Gain is also improved in the proposed antenna. Bandwidth improvement and shifting of resonant frequency to higher frequency region at three frequency bands are observed, but gain improvement occurred at third frequency band. The $860-960 \mathrm{MHz}$ ISM band is utilized for passive UHF RFID in different countries. So first band 0.86135-0.90821 with center frequency $0.88412 \mathrm{GHz}$ is suitable for RFID application. The two higher bands 2.1822-2.3955 with center frequency $2.278 \mathrm{GHz}$ and $3.5959-3.8054$ with center frequency $3.6952 \mathrm{GHz}$ are suitable for WLAN/WiMAX applications. 

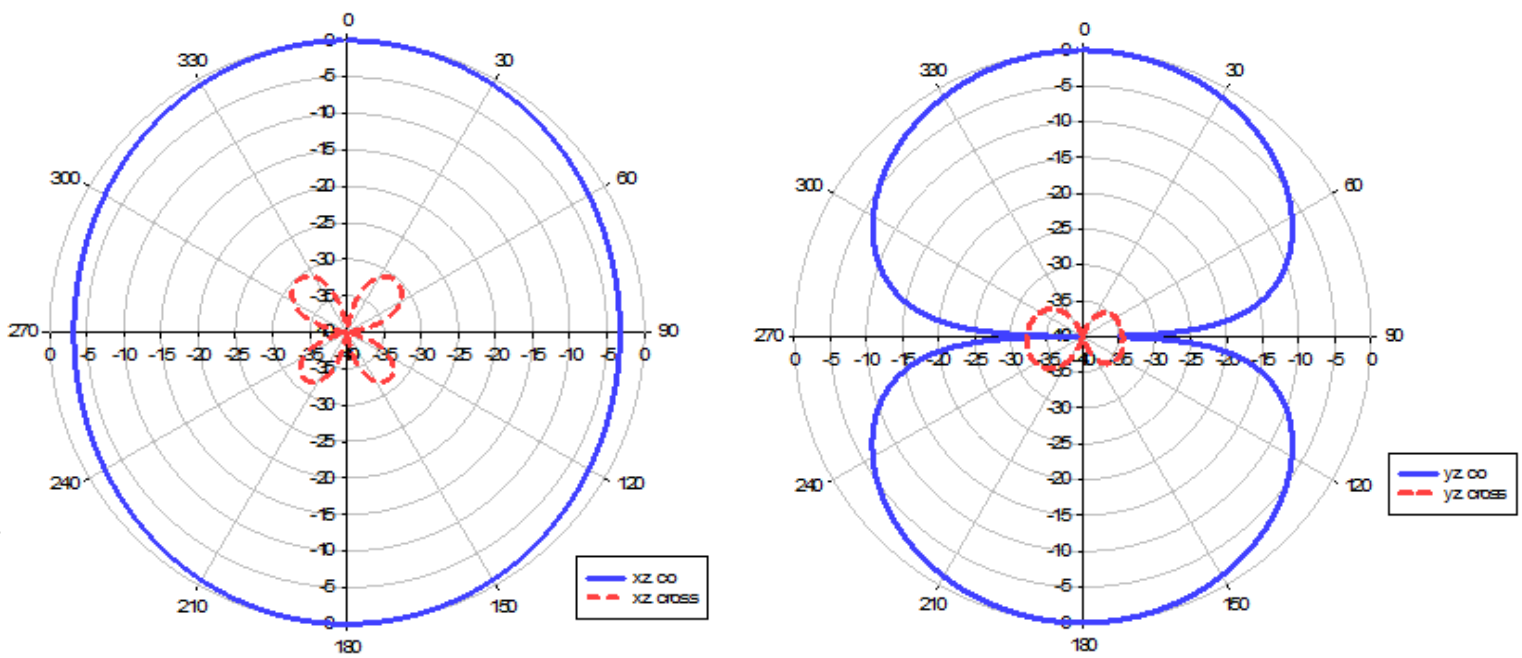

Figure 4. Radiation patterns in different planes at $0.88414 \mathrm{GHz}$
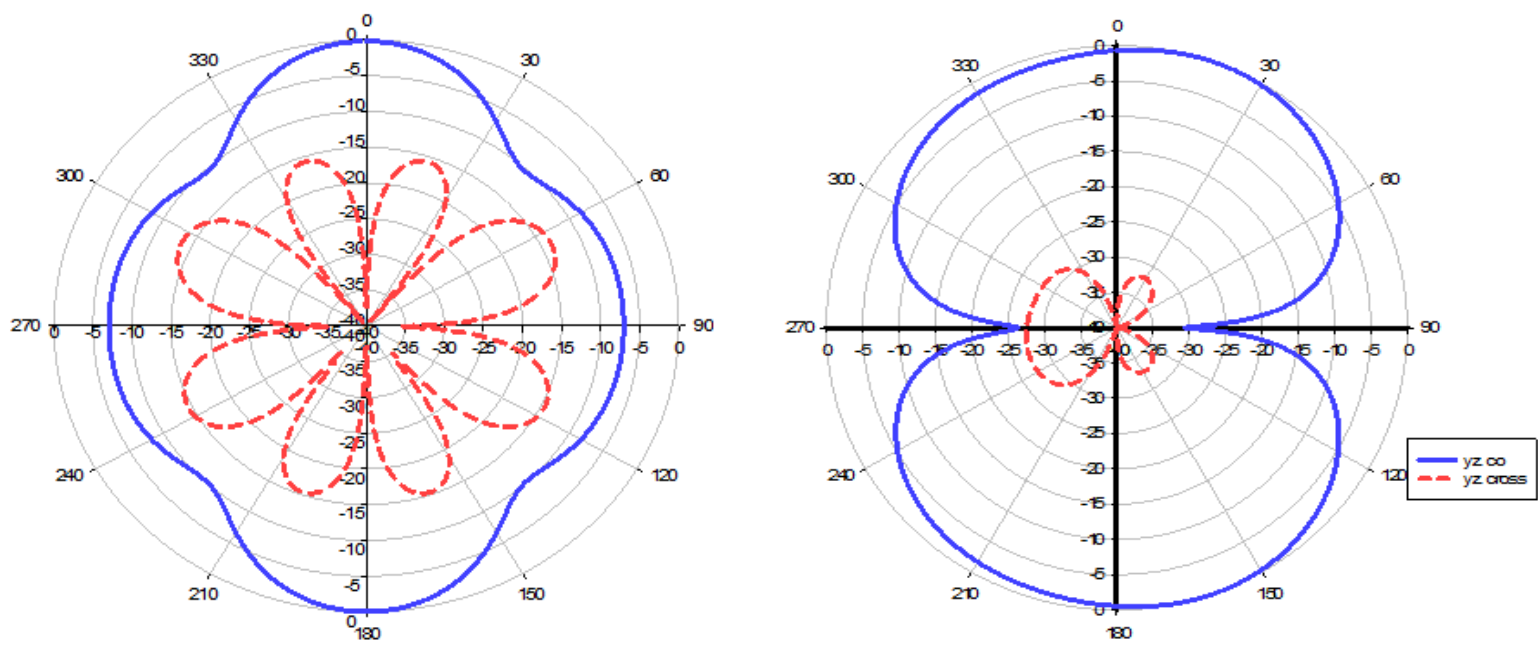

Figure 5. Radiation patterns in different planes at $\mathrm{f}=2.787 \mathrm{GHz}$
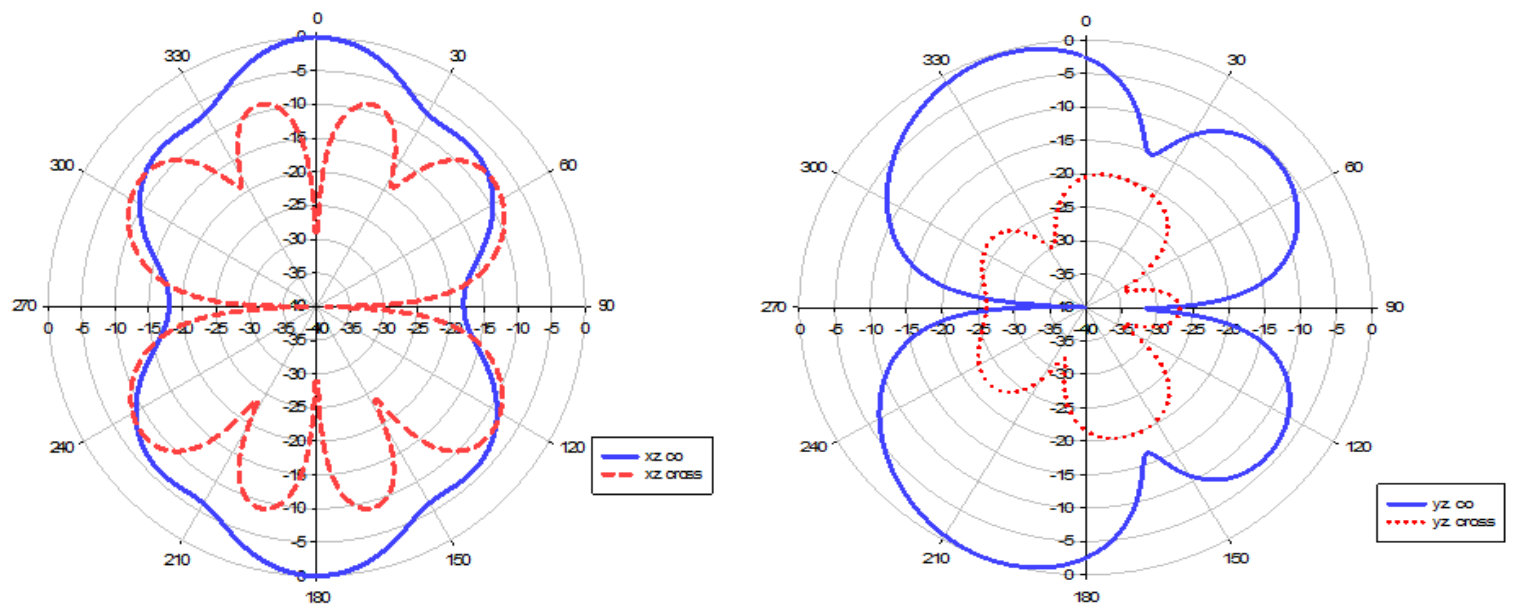

Figure 6. Radiation patterns in different planes at $\mathrm{f}=3.6987 \mathrm{GHz}$ 
Table 3. Comparison chart of the proposed antenna and recently published paper for triple band operations

\begin{tabular}{cccc}
\hline Parameter & Ref.[24] & Ref.[25] & Proposed Work \\
\hline Resonant frequency $(\mathrm{GHz})$ & $2.45,3.5$ and 5.5 & $2.45,3.5$ and 5.5 & $0.8941,2.27$ and 3.701 \\
Gain $(\mathrm{dBi})$ & $3.73,3.2$ and 4.2 & $2.1,2$ and 2.98 & $2.98,5.66$ and 8.91 \\
Size $\left(\mathrm{mm}^{2}\right)$ & $25 \times 18$ & $40 \times 36$ & $154 \times 100$ \\
\hline
\end{tabular}

\section{CONCLUSION}

This work has presented a CPW fed SRR loaded planar monopole antenna with tapered SRR. Tapering has been developed with edges of non-uniform dimensions based on the current and voltage distribution in the SRR structure. By this modification, the bandwidth is improved and the resonant frequencies are shifted towards a higher frequency side. This strong and wideband resonance is required in many applications-the lower band can be used for UHF RFID applications and higher bands are applicable to WLAN/WiMAX applications. Further modifications will lead to an increase in bandwidth and multiband characteristics.

\section{REFERENCES}

[1] Balanis C. A., "Antenna theory analysis and design, 3rd edition," Wileterscience publication $3^{\text {rd }}, 2005$.

[2] R. Zaker and A. Abdipour, "A Very Compact Ultra wideband Printed Omnidirectional Monopole Antenna," in IEEE Antennas and Wireless Propagation Letters, vol. 9, pp. 471-473, 2010.

[3] Yong-Sun Shin, Seong-Ook Park and Manjai Lee, "A broadband interior antenna of planar monopole type in handsets," in IEEE Antennas and Wireless Propagation Letters, vol. 4, pp. 9-12, 2005.

[4] A. Foudazi, H.R. Hassani and S. Mohammad ali nezhad, "Small UWB Planar Monopole Antenna With Added GPS/GSM/WLAN Bands," in IEEE Transactions on Antennas and Propagation, vol. 60, no. 6, pp. 2987-2992, Jun. 2012.

[5] G. Augustin and T. A. Denidni, "Coplanar Waveguide-Fed Uniplanar Trapezoidal Antenna With Linear and Circular Polarization," in IEEE Transactions on Antennas and Propagation, vol. 60, no. 5, pp. 2522-2526, 2012.

[6] Sze, J.Y., C.I.G. Hsu, Z.W. Chen and C.C. Chang, "Broadband CPW-fed circularly polarized square slot antenna with lightning-shaped feed line and inverted-L grounded strips," IEEE Trans. Antennas Propag., vol. 58, no. 3, 2010.

[7] V.G. Veselago, "The Electrodynamics of Substances with Simultaneously Negative Values of $\varepsilon$ and $\mu$," Soviet Physics, vol. 10, pp. 517-526, Feb. 1968.

[8] J.B. Pendry, A.J. Holden, D.J. Robbins and W.J. Stewart, "Magnetism from conductors and enhanced nonlinear phenomena," in IEEE Transactions on Microwave Theory and Techniques, vol. 47, no. 11, pp. 2075-2084, 1999.

[9] D.R. Smith, Willie J. Padilla, D.C. Vier, S.C. Nemat-Nasser, and S. Schultz, "Composite Medium with Simultaneously Negative Permeability and Permittivity," Phys. Rev. Lett., vol. 84, May 2000.

[10] F. Qureshi, M.A. Antoniades and G.V. Eleftheriades, "A compact and low-profile metamaterial ring antenna with vertical polarization," in IEEE Antennas and Wireless Propagation Letters, vol. 4, pp. 333-336, 2005.

[11] A. Erentok and R.W. Ziolkowski, "Metamaterial-Inspired Efficient Electrically Small Antennas," in IEEE Transactions on Antennas and Propagation, vol. 56, no. 3, pp. 691-707, Mar. 2008.

[12] J. Baena, R. Marques, F. Medina, and J. Martel, "Artificial magnetic metamaterial design by using spiral resonators," Phys. Rev. B, vol. 69, no. 1, Article 014402, 2004.

[13] D.K. Ntaikos, N.K. Bourgis and T.V. Yioultsis, "Metamaterial-Based Electrically Small Multiband Planar Monopole Antennas," in IEEE Antennas and Wireless Propagation Letters, vol. 10, pp. 963-966, 2011.

[14] M.A. Antoniades and G.V. Eleftheriades, "A Broadband Dual-Mode Monopole Antenna Using NRI-TL Metamaterial Loading," in IEEE Antennas and Wireless Propagation Letters, vol. 8, pp. 258-261, 2009.

[15] X.Q. Lin and T.J. Cui, "Controlling the Bandwidth of Split Ring Resonators," in IEEE Microwave and Wireless Components Letters, vol. 18, no. 4, pp. 245-247, Apr. 2008.

[16] A.K. Horestani, C. Fumeaux, S.F. Al-Sarawi and D. Abbott, "Split Ring Resonators With Tapered Strip Width for Wider Bandwidth and Enhanced Resonance," in IEEE Microwave and Wireless Components Letters, vol. 22, no. 9 , pp. 450-452, Sep. 2012.

[17] N.P. Agrawall, G. Kumar and K.P. Ray, "Wide-band planar monopole antennas," in IEEE Transactions on Antennas and Propagation, vol. 46, no. 2, pp. 294-295, Feb. 1998.

[18] S. Ahdi Rezaeieh, A. Abbosh and M.A. Antoniades, "Compact CPW-Fed Planar Monopole Antenna with Wide Circular Polarization Bandwidth," in IEEE Antennas and Wireless Propagation Letters, vol. 12, pp. 1295-1298, 2013.

[19] Finkenzeller K., "RFID Handbook: Radio -frequency Identification, fundamentals and Applications," 3rd Edition, Wiley, 2010.

[20] Ahmed El Hamraoui, EL Hassane Abdelmounim, Jamal Zbitou, Hamid Bennis, Mohamed Latrach, "A New Design of a CPW-Fed Dual-Band Monopole Antenna for RFID Readers," International Journal of Electrical and Computer Engineering (IJECE), vol. 8, no. 2, pp. 1040 1047, Apr. 2018.

[21] Niranjan V., A.K. Saxena, and K.V. Srivastava, "CPW-fed slot patch antenna for 5.2/5.8 GHz WLAN application," PIERS Proceedings, Kuala Lumpur, Malaysia, pp. 1350-1352, Mar. 2012. 
[22] Liang Dong, Zhiya Zhang, Wang Li, and Guang Fu, "A Compact CPW-Fed monopole antenna with triple bands for WLAN/WiMAX applications," Progress In Electromagnetics Research Letters, vol. 39, pp. 103-113, 2013.

[23] P.L. Shu and Q. Y. Feng, "Compact tri-band monopole antenna with a parasitic e-shaped strip for WLAN/WiMAX applications," Progress In Electromagnetics Research C, vol. 32, pp. 53-63, 2012.

[24] X.Q. Zhang, Y.-C. Jiao, and W.H. Wang, "Miniature triple-band cpw-fed monopole antenna for WLAN/WiMAX applications," Progress In Electromagnetics Research Letters, vol. 31, pp. 97-105, 2012.

[25] Leila Chouti, Idris Messaoudene, Tayeb A., Denidni, and Abdelmadjid Benghalia, "Triple-Band CPW-Fed Monopole Antenna for WLAN/WiMAX applications," Progress In Electromagnetics Research Letters, vol. 69, pp. 1-7, 2017.

\section{BIOGRAPHIES OF AUTHORS}

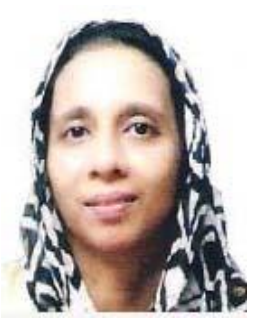

Smitha K. M. was born in Kerala, India on $17^{\text {th }}$ March 1978. She received her Bachelor's degree in Electronics \& Communication from Cochin University of Science and Technology Cochin, in 2002 and a Master's degree in Communication Systems from Anna University, Chennai, Tamilnadu, India, in 2012. She has over 15 years of experience in various professional institutions in Kerala and is presently working as Head of the Department of Electronics and Communication, KMEA Engineering College, Kerala, India. She is currently pursuing her Ph.D. degree in Microwave Electronics at School of Technology \& Applied Sciences, Mahatma Gandhi Univerisity Regional Center, Edappally, Kochi. Her current areas of research include CPW fed monopole antennas and microstrip antennas with fractals and metamaterials, EMC/EMI, etc. She is a life member of the Institute of Electronics and Telecommunication Engineers and the Institution of Engineers, India.

Tel: (+91) 9497545701

E-mail: smithariyaz@gmail.com

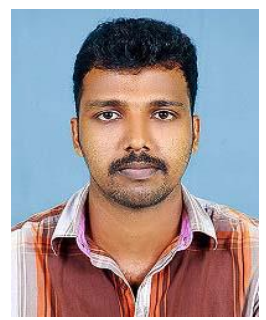

Aju John K. K. was born in Kerala, India on 30th May 1984. He received his Bachelor's Degree in Electronics from the University of Kerala, in 2004 and MSc in Electronics from Bharathidasan University, Thiruchirappally in 2006 and MTech in Electronics from Cochin University of Science and Technology, Cochin, in 2010. He is currently pursuing his Ph.D. Degree in Microwave Electronics at School of Technology \& Applied Sciences, Mahatma Gandhi Univerisity Regional Center, Edappally, Kochi. His current areas of research include RFID Tag and Antennas, Metamaterials and Metasurfaces, etc

Tel: (+91) 7012078164

E-mail: ajujohnkk@gmail.com

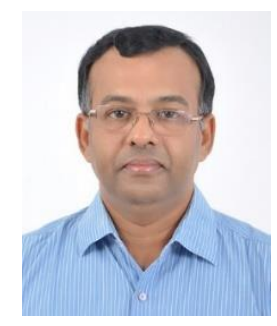

Thomaskutty Mathew was born in Kerala, India on $30^{\text {th }}$ May 1967. He received his Ph.D. Degree in Microwave Electronics from Cochin University of Science and Technology Cochin, India in 1997. From 1995 to 1999 he worked as a Lecturer in Physics at Christ College, Irinjalakuda, India. From 1999 to 2018, he worked as a faculty of the Department of Electronics, School of Technology \& Applied Sciences, Mahatma Gandhi University Regional Center, Edappally, Kochi, India. Presently, he is working as an Associate professor in Physics in the School of Technology, GITAM University, Bengaluru campus, India. During the period 2006-2008, he worked as a PostDoctoral Research Associate at the Department of Electronics, University of Kent, Canterbury, the U.K. His current area of research activities are in Microstrip antennas, Radar Cross Section, RFID, Wireless Sensor Networks, etc. He is a member of the IEEE Antennas and propagation society and IET (U.K).

Tel: (+91) 9048108856

E-mail: drtkmathew@gmail.com 